\title{
Equity and medical practice variation: relationships between standardised discharge ratios in total and for selected conditions in English districts
}

\author{
C E Price, E A Paul, R G Bevan, W W Holland
}

\begin{abstract}
Study objective-The aim was to investigate relationships for residents of English district health authorities between rates of discharges from acute hospitals for all conditions and variations in discharge rates for eight common conditions (five surgical, three medical).
\end{abstract}

Design-Hospital Inpatient Enquiry data on discharges for 1984 were analysed. Standardised discharge ratios (ratios of actual to expected numbers of discharges $x$ 100) were derived for selected conditions and all conditions; and correlation coefficients for these statistics were calculated. Districts were grouped into quintiles according to the value of the standardised discharge ratio, and systematic variation within each quintile was calculated for the selected conditions.

Setting-The study involved all 192 English district health authorities, but 57 were excluded because the proportion of unspecified diagnoses exceeded $5 \%$.

Patients-The analyses were based on 336799 cases from 135 districts.

Measurements and main resultsDischarge ratios for the medical conditions and one surgical condition were significantly correlated with the levels of total discharge rates $(p<0.01)$. The medical conditions showed greater systematic variation in discharge ratios than the surgical conditions. There was no consistent pattern in the values of systematic variation for the selected conditions across the different levels of discharge ratios for all conditions.

Conclusions-It is argued that the changes in the NHS introduced in April 1991 are intended to introduce greater equity in the standardised discharge ratios and increase the total numbers of discharges. The results of this analysis suggest that, even if these objectives were achieved, they may not result in increased levels of elective care, nor result in greater equity in terms of rates of discharge for individual conditions.

The pursuit of equity in resources between health authorities in England has been a stated objective of the NHS since 1975, when the Government set the terms of reference of the Resource Allocation Working Party (RAWP). ${ }^{1}$ The underlying objective of the terms of reference was interpreted by RAWP to mean that "through resource allocation...there would eventually be equal opportunity of access to health care for people at equal risk". ${ }^{1}$ The policy recommended by RAWP was to move health authority allocations of resources towards targets based on resident populations with adjustments for cross boundary flows (people living in one authority but treated in another), the extra service costs of teaching medical and dental undergraduates (the Service Increment for Teaching-SIFT), and the higher pay of those working in London (London weighting-and subsequently London market forces). Since 1975, Government policy has been to move regions' allocations towards regional targets, and for regions to apply similar policies subregionally.

There has been dispute over the adequacy of RAWP methods in accounting for the relative needs of resident populations and the various adjustments. ${ }^{2}$ Analysis has shown that the driving force behind moving district allocation towards targets is the capitation element-the allowance in the target for district residents' use of resources (based on national average utilisation rates weighted by age and sex and a surrogate measure of morbidity such as standardised mortality ratios). Where the annual cost of use of services by residents of a district exceeds their capitation element, then reductions are required in the district's allocation. ${ }^{34}$ In this way the policy implicit in RAWP methods is one of equalising total spending per capita by residents of English health authorities. This became explicit in the new system of district finance introduced in April $1991 .^{5}$

Equalising spending per capita may not, of course, equalise access to services. Of particular concern to the Government was the variation in performance: ${ }^{5}$

"New management information systems have provided clear evidence of a wide variation in performance up and down the country. In 198687 , the average cost of treating acute hospital inpatients varied by as much as $50 \%$, between different health authorities, even after allowing for the complexity and mix of cases treated. Similarly, a patient who waits several years for an operation in one place may get that same operation within a few weeks in another".

Such variations are of concern, but were not addressed by RAWP, although its terms of reference mentioned efficiency. It is difficult to see how RAWP could have recommended methods to promote efficiency given the way the NHS was structured. If, for example, authorities' allocations were adjusted to give more resources to the more efficient authorities, then this would conflict with the objective of equity: residents 
of inefficiently managed authorities would be doubly penalised; they would receive less than their fair share of resources and these resources would be poorly used. To be equitable it would seem necessary to give more resources to poorly managed authorities, but that would generate perverse incentives.

"Working for Patients"5 appears to provide a neat solution to the pursuit of both equity and efficiency: districts will be funded equitably by capitation for their residents, but then pursue efficiency through acting as prudent purchasers choosing between competing suppliers. The objectives of these policies are to reduce variation in, and mean values of, costs per case and waiting times. If costs per case were reduced, then districts would be able to increase the number of acute cases they paid for out of their capitation based allocations.

But, if the reforms did achieve their intended objectives, would they result in greater equity in terms of the equal likelihood of being treated for the same conditions? A common feature of the United Kingdom, North American, and many European systems of health care is the wide variation in treatment rates for the same condition between geographical areas in the same country. ${ }^{6-8}$ Variations in these rates far exceed the likely variation in morbidity which suggests inequity of treatment.

The systems of financing hospital services implemented from April $1991^{5}$ will continue to equalise total resources per capita allocated to district populations, and seek to introduce competition between providers. If this competition results in reduced variation in costs per case, this, together with equalising available resources per capita, would reduce variation in total discharge rates between districts. Would this also be likely to reduce variation in rates of treatment for individual conditions? If competition resulted in continued reductions in costs per case, it could result in increases in total treatment rates. Would increases in total treatment rates reduce variation in rates of treatment for individual conditions and in this way reduce waiting times?

"Working for Patients" implies a link between the objectives of increasing hospital admissions and reducing waiting times. The hypothesis underlying this link may be that higher levels of total rates of treatment will result in a common level of rates for the emergencies (the majority of which are medical conditions, which together account for significant amount of resources), but increased levels of rates for elective conditions. The hypothesis is, however, at variance with consistent published findings on medical practice variations: that there is greater variation in discharge rates for medical than for surgical conditions. ${ }^{7-10}$

The large variation in rates of discharge from hospital consistently reported for medical and surgical conditions is often attributed to medical discretion and variations in access by populations to "supply". 7 As McPherson et al "1 point out, however, the same measures of "supply" are likely to have different meanings in different countries according to the different methods of paying hospital doctors and other hospitals. These may explain the differences they found in variation in surgical rates between North America and the United Kingdom. In the USA and Canada, "Parkinson's law of surgery" applied (the more surgeons, the more surgery): there was a strong correlation between surgical rates and surgical manpower. In contrast, in England and Wales, there was only a weak correlation. They hypothesise that the reason for these differences is the budget constraint which applies to hospital services in England and Wales.

The US system of payment of fees to physicians and charges to hospitals was based on "reasonable" charges for unregulated volumes. In this system, it seems plausible to assume that the medical practice variation observed arose from a lack of consensus over the levels of treatment at which some benefit is produced for patients regardless of costs. McPherson et al ${ }^{11}$ point out that given scope for supplier induced demand, there is likely to be no constraint on total numbers of surgical cases, and hence there is no real threat to incomes of surgeons from the actions of other surgeons.

Doctors in the United Kingdom NHS may in the past have claimed clinical autonomy from resource constraints, but this makes sense as a rhetorical claim only: a global budget constraint applied. Hence, in the United Kingdom there is competition between doctors in different specialties for resources, which is likely to mean that doctors are unable to secure the levels of treatment they would ideally like to provide. This could be another factor contributing to medical practice variation in addition to differences of opinion over appropriate levels of treatment between doctors treating the same conditions.

The question explored here is whether the degree of tightness of the budget constraint (as indicated by levels of total hospital discharge rates for the resident populations of English districts) contributes to medical practice variation. Holland $^{12}$ hypothesised that competition for resources could contribute to variation in discharge rates in the United Kingdom, and that, as this competition diminished through increased availability of resources, there would be a convergence in medical practice and hence reduced variation in condition specific discharge rates. Published reports on medical practice variation have not considered explicitly the relations between levels of total discharge rates and variation in rates for individual conditions.

In the USA, studies have reported variation in rates for surgical conditions consistent with Wennberg's hypothesised "surgical signature" in which unique surgical use rate patterns exist in each hospital service area regardless of the level of total rates. ${ }^{10} 13$ Wennberg and Gittelson, ${ }^{13}$ for example, in their study of common surgical procedures in Maine, found in five large contiguous areas (three of which had similar overall rates of surgery) that the procedure performed most frequently was different in each area, and the procedure performed least frequently was different in four of the five areas. In contrast US studies of medical conditions have found positive correlations between discharge rates for each condition and total discharge 
rates. ${ }^{8-10}$ The examination by Wennberg et al ${ }^{14}$ of higher rates of use of services by the residents of Boston as compared with New Haven, found that the conditions accounting for most of the increased consumption were medical, and these medical conditions were ones for which previous studies had shown discharge rates to vary considerably across small areas.

In the United Kingdom, McPherson et al ${ }^{11}$ found that surgical rates at regional level in England were correlated with a measure of "excess" funds-the extent to which regions" allocations exceeded their RAWP targets-but were unable to disentangle this effect from the measure of density of general practitioners, which was also strongly correlated with the measure of excess funds. Holland ${ }^{12}$ reported that that variation in discharge rates for selected medical and surgical conditions in six districts in South East Thames Regional Health Authority was negatively correlated with availability of resources (indicated by spending per capita measured by their allocation in comparison with their subregional RAWP targets). His results supported his hypothesis that competition for resources did contribute to medical practice variation.

In examining variation in discharge rates, it is essential to account for the different levels of random variation to be expected. Where the discharge rate is low, with a low number of events, the contribution of random variation to the total variation is higher than where rates are high. Only after this variation has been accounted for is it possible to identify systematic variation which can then be related to total levels of resources. ${ }^{11}$ Holland's study ${ }^{12}$ was unable to identify this systematic variation because of the small number of residential areas chosen. Hence it is not possible to infer from that study whether increases in total levels of resources did or did not result in more or less systematic variation in admission rates.

This paper reports systematic variation in discharges in total and for selected conditions for 192 English districts. These data are analysed to examine whether (1) they confirm the finding of greater variation in medical (as opposed to surgical) conditions; (2) districts with higher levels of total discharges appear to have a constant level of discharges for emergency conditions, but increased levels of discharges for the elective conditions; and (3) variation in discharge rates for each condition is reduced for districts with higher total levels of discharge rates.

\footnotetext{
Methods

Data on discharges for resident populations of the 192 English health districts were obtained from the 1984 Hospital Inpatient Enquiry (HIPE) supplied by the Office of Population Censuses and Surveys on magnetic tape. This contained a one in 10 sample of all discharges from NHS hospitals, excluding psychiatric and convalescent hospitals and maternity units. Information was included for each discharge (including day cases) on district of residence, main diagnosis coded to the International Classification of Diseases (ICD) four digit code, main operation coded to the OPCS operation code, ${ }^{15}$ and sex and age.
}

The conditions examined were abdominal hernia operations, hip replacement, mastectomy, diabetes, myocardial infarction, appendicectomy, cholecystectomy, and cerebrovascular disease. The first five conditions are those for which Holland ${ }^{12}$ found that admission rates varied inversely with resources in six South East Thames Regional Health Authority districts. Appendicectomy, cholecystectomy, and cerebrovascular disease were added because of their importance in terms of numbers of admissions and bed use.

Examination of discharge rates by diagnosis revealed some districts with a high proportion of discharges where the diagnosis was unspecified. The most common reason for this was that the district was unable to provide diagnostic information. ${ }^{16}$ Since it is possible that missing diagnostic information is concentrated in particular specialties, districts were omitted from the analysis of variation in hospital use where the proportion of unspecified diagnoses was greater than 5\%. After excluding such districts, 135 districts remained for further analysis.

The standardised discharge ratio for each condition was calculated as the ratio of the actual to the expected number of discharges multiplied by 100 . Expected rates were derived from age and sex specific counts for the total 135 districts for nine age groups for each sex. These were then applied to district populations taken from OPCS estimates ${ }^{17}$ using the indirect method of standardisation.

Pearson correlation coefficients were used to relate the standardised discharge ratio for each condition to the total discharge ratio (total discharges for all causes standardised by age and sex). Districts were assigned to one of five categories by ranking the total discharge ratio and dividing it into quintiles. For each condition the systematic component of variance of the standardised discharge ratio for each cause was calculated within each quintile. The systematic component of variance is a measure of the variability of the standardised admission ratio for districts after differences in district population size and differences in estimated levels of morbidity have been taken into account. The method was described by McPherson et al. ${ }^{11} \mathrm{~F}$ ratios were used to compare the systematic component of variation of standardised discharge ratios for each condition within each quintile.

\section{Results}

The total number of hospital discharges of patients in the HIPE sample was 494772 . Fifty seven districts had a proportion of cases with unspecified diagnoses ranging from $5 \%$ to $80 \%$; these districts were excluded from further analysis, leaving 336799 cases from 135 districts.

The standardised discharge ratio for all diagnoses combined ranged from 63 to 156 which would represent differences in discharges for an averaged sized district population of 240000 of between 16000 and nearly 40000 per year.

Table I gives, for the selected conditions/ operations and for all discharges, the total numbers of discharges, mean discharge rates, and the 5th and 95th centile range for discharge rates, standardised by age and sex. 
Table I Discharge rates for resident populations of 135 English health districts

\begin{tabular}{|c|c|c|c|}
\hline Condition & $\begin{array}{l}\text { Number of } \\
\text { discharges } \\
\text { in sample }\end{array}$ & $\begin{array}{l}\text { Mean discharge } \\
\text { rates per } 10000 \\
\text { population }\end{array}$ & $\begin{array}{l}\text { 5th-95th centile range } \\
\text { range in districts per } \\
10000 \text { standardised for }\end{array}$ \\
\hline \multicolumn{4}{|l|}{ Appendicectomy } \\
\hline $\begin{array}{l}\text { (OPCS 441, 443, 444) } \\
\text { Cholecystectomy }\end{array}$ & 3658 & $11 \cdot 3$ & $6 \cdot 4-19 \cdot 7$ \\
\hline (OPCS 522) & 2484 & $7 \cdot 7$ & $3 \cdot 3-13 \cdot 0$ \\
\hline $\begin{array}{l}\text { Hernia operations } \\
\text { (OPCS } 410-412,415-419)\end{array}$ & 6022 & $18 \cdot 6$ & $13 \cdot 4-26 \cdot 0$ \\
\hline Hip replacement & & & \\
\hline $\begin{array}{l}\text { (OPCS 810, 811) } \\
\text { Mastectomy }\end{array}$ & 2673 & $8 \cdot 3$ & $4 \cdot 0-13 \cdot 2$ \\
\hline $\begin{array}{l}\text { Mastectomy } \\
\text { (OPCS 382-385) } \\
\text { Cerebrovascular disease }\end{array}$ & 2617 & $8 \cdot 0$ & $3 \cdot 4-13 \cdot 2$ \\
\hline (ICD 430-438) & 8286 & $25 \cdot 6$ & $17 \cdot 4-41 \cdot 0$ \\
\hline $\begin{array}{l}\text { Diabetes } \\
\quad(\text { ICD 250) } \\
\text { Myocardial infarction }\end{array}$ & 3566 & $11 \cdot 0$ & $5 \cdot 8-20 \cdot 7$ \\
\hline All $($ ICD 410) & 7720 & $23 \cdot 8$ & $12 \cdot 9-48 \cdot 1$ \\
\hline (ICD all codes) & 336799 & 1039 & $810-1320$ \\
\hline
\end{tabular}

Table II Variations in standardised discharge ratios (SDR) for resident populations of 135 English health districts 1984

\begin{tabular}{|c|c|c|c|c|}
\hline & \multirow{2}{*}{$\begin{array}{l}\text { Number of } \\
\text { discharges } \\
\text { in sample }\end{array}$} & \multicolumn{2}{|l|}{$S D R$} & \multirow{2}{*}{$\begin{array}{l}\text { Systematic } \\
\text { variance } \\
\text { of } S D R^{\star}\end{array}$} \\
\hline & & 5th centile & 95th centile & \\
\hline \multirow{4}{*}{$\begin{array}{l}\text { Appendicectomy } \\
\text { (OPCS 441, 443, 444) } \\
\text { Cholecystectomy } \\
\text { (OPCS } 522 \text { ) } \\
\text { Hernia operations }\end{array}$} & & & & \\
\hline & 3658 & 56 & 171 & 0.051 \\
\hline & 2484 & 40 & 163 & 0.040 \\
\hline & & & & 0.040 \\
\hline (OPCS 410-412, 415-419) & 6022 & 69 & 133 & 0.013 \\
\hline $\begin{array}{l}\text { Hip replacement } \\
\text { (OPCS 810, 811) }\end{array}$ & 2673 & 48 & 159 & 0.048 \\
\hline Mastectomy & & & & \\
\hline $\begin{array}{l}\text { (OPCS 382-385) } \\
\text { Cerebrovascular disease }\end{array}$ & 2617 & 41 & 165 & 0.082 \\
\hline $\begin{array}{l}\text { (ICD 430-438) } \\
\text { Diabetes }\end{array}$ & 8286 & 64 & 151 & 0.061 \\
\hline (ICD 250) & 3566 & 51 & 180 & 0.074 \\
\hline $\begin{array}{l}\text { Myocardial infarction } \\
\text { (ICD 410) }\end{array}$ & 7720 & 48 & 189 & 0.129 \\
\hline
\end{tabular}

*The variance remaining after subtraction of the amount of the variance estimated to be due to random variation

Table III Correlation coefficients between standardised discharge ratios for specific conditions and total standardised discharges for 135 English health districts 1984

\begin{tabular}{|c|c|}
\hline & $\begin{array}{l}\text { Correlation } \\
\text { coefficient }\end{array}$ \\
\hline $\begin{array}{l}\text { Appendicectomy } \\
\text { (OPCS } 441,443,444)\end{array}$ & \\
\hline $\begin{array}{l}\text { (OPCS 441, 443, 444) } \\
\text { Cholecystectomy }\end{array}$ & $0 \cdot 14$ \\
\hline (OPCS 522) & $0 \cdot 30^{\star}$ \\
\hline Hernia operations & \\
\hline (OPCS 410-412, 415-419) & $0 \cdot 16$ \\
\hline $\begin{array}{l}\text { Hip replacement } \\
\text { (OPCS } 810,811)\end{array}$ & -0.15 \\
\hline Mastectomy & \\
\hline $\begin{array}{l}\text { (OPCS 382-385) } \\
\text { Cerebrovascular disease }\end{array}$ & $0 \cdot 17$ \\
\hline $\begin{array}{l}\text { Cerebrovascular disease } \\
\text { (ICD 430-438) }\end{array}$ & $0 \cdot 40$ 夫 \\
\hline $\begin{array}{l}\text { Diabetes } \\
\quad(\text { ICD 250) }\end{array}$ & $0.56^{\star}$ \\
\hline $\begin{array}{l}\text { Myocardial infarction } \\
\text { (ICD 410) }\end{array}$ & $0 \cdot 74^{\star}$ \\
\hline
\end{tabular}

Table IV Variation in standardised discharge ratios (SDR) for resident districts across five levels of discharge ratio

\begin{tabular}{lllllll}
\hline \multicolumn{7}{l}{ Total discharge ratio } \\
\cline { 2 - 7 } & $\begin{array}{l}\text { Lowest } \\
\text { quintile }\end{array}$ & & & & \\
\hline & 1 & 2 & 3 & 4 & $\begin{array}{l}\text { Highest } \\
\text { quintile }\end{array}$ \\
\hline Appendicectomy & 0.0362 & 0.0494 & 0.0281 & 0.0718 & 0.0656 \\
Cholecystectomy & 0.0222 & 0.0130 & 0.0478 & 0.0443 & 0.0383 \\
Hernia operations & 0.0115 & 0.0056 & 0.0146 & 0.0243 & 0.0016 \\
Hip replacement & 0.0202 & 0.0331 & 0.0772 & 0.0166 & 0.0197 \\
Mastectomy & 0.0343 & 0.0933 & 0.0282 & 0.1736 & 0.0751 \\
Cerebrovascular disease & 0.0339 & 0.0385 & 0.0156 & 0.0790 & 0.0854 \\
Diabetes & 0.0121 & 0.0267 & 0.0439 & 0.0219 & 0.1474 \\
Myocardial infarction & 0.0135 & 0.0170 & 0.0231 & 0.0507 & 0.1720 \\
\hline
\end{tabular}

Each quintile contains 27 districts. The ratio of variation between two quintiles may be compared with the percentage points of the $F$ distribution on 26,26 degrees of freedom. $\mathrm{F}_{26,26}=1.94$
Table II gives the 5 th and 95 th centiles of the standardised discharge ratio and the systematic component of variation for each condition. The systematic variation between districts was greater for each of the medical conditions than for each of the surgical conditions, with the exception of mastectomy.

Table III shows that the total discharge ratio was significantly positively correlated with the standardised discharge ratio for myocardial infarction, diabetes, cerebrovascular disease, and cholecystectomy, but not with those for appendicectomy, inguinal herniorrhaphy, hip replacement, or mastectomy. Since the discharges for individual conditions contribute to the total number of discharges it might be thought tautological that discharges from individual conditions would correlate with total discharges. However, none of the individual conditions formed more than $2.5 \%$ of total discharges and the size of the correlation coefficient was not dependent on the overall number of discharges for each condition.

Table IV gives systematic variation of discharge rates for the selected conditions for district groups in quintiles according to the total discharge ratio. This table shows that there is no consistent relationship between systematic variation and total levels of discharge ratios.

\section{Discussion}

\section{ARTEFACTUAL VARIATION}

District admission rates measured from the Hospital Inpatient Enquiry may vary not only because of differences in supply and clinical practice, but also through artefacts in the data, differences in the provision of private care, or differences in morbidity. It is possible to estimate hospital discharge rates for the population of districts because HIPE contains information on both district of treatment and district of residence. A potential problem arises because HIPE is based on individual episodes of discharge rather than individual patients. Thus, if a patient returns to hospital several times for treatment for the same condition this will inflate the discharge rate for that district for that condition. Another possible source of artefactual variation in discharge rates could arise from differences in diagnostic and coding practices between districts. This is likely to be more important in medical conditions, where patients commonly have several diagnoses, than in surgical operations. The effect of the private sector on district utilisation rates is hard to quantify, but is not negligible. It was estimated that in $198113 \%$ of all elective surgery was undertaken privately and the regional difference in the provision of private acute beds ranged from 3 per 100 to 46 per $1000 .^{18}$ Despite these problems of measurement and area differences in morbidity it is unlikely that these would account for the twofold to fourfold differences found in all the eight conditions.

ELECTIVE AND EMERGENCY CARE

The results reported in table II confirm general findings of studies of medical practice variation that there is greater variation in medical than in surgical conditions. 
The vast majority of medical admissions are emergencies. The variation in medical rates highlights the ambiguity surrounding the definition of an "emergency". Therefore, throughout the country, people at equal risk from myocardial infarction and cerebrovascular disease have different rates of admission to hospital, although once the decision to admit has been made, it will almost certainly be an "emergency". In other conditions where we have reported variation in discharge ratios there will be a grey area over whether a condition is or is not an emergency: for example, hernia, mastectomy, diabetes.

Do districts with higher rates of discharges in total tend to have higher elective discharge rates, higher emergency discharges or both? We found evidence that total discharge ratios were correlated with the condition specific discharge ratios for three common medical conditions but only one of five common surgical conditions; to take striking contrasting examples: health authorities with higher total admission per capita treat more cases with myocardial infarction and cerebrovascular disease (emergencies) but no more hip replacements (elective). These results show not only that in England, as in the USA, variation in discharge rates for medical conditions is greater than for surgical conditions, but also that this applies having taken account of the total level of discharges for all conditions.

MEDICAL DISCRETION AND RESOURCE CONSTRAINTS Do districts with higher rates of discharges in total tend to have less variation in rates of discharges for the same conditions? Holland ${ }^{12}$ produced evidence supporting the hypothesis that variation is a product of competition for scarce services, and as the level of services increases the variation is reduced. Our results lead us to reject this hypothesis: there is no reduction in variation of condition specific discharge ratios as total discharge ratios increase. For the conditions chosen, there is no consistent pattern in variation and level of discharges except for myocardial infarction where there is increased variation with increased levels of discharges.

Our results emphasise the importance of understanding medical discretion-a common factor identified in publications in this field. The lack of evidence in our study that resource constraints contribute to the systematic variation in discharge rates may also be explained by medical discretion. Medical politics operate within a global budget constraint to decide who gets what. These negotiations are based on trade offs between different doctors' views of the benefits (or losses) from expanding (or contracting) their levels of service. Hence these views may be given doubled force within resource constraints: they influence both negotiations over resources and how those resources are used to provide levels of treatment.
EQUITY AND EFFICIENCY

The purpose of this paper has been to relate questions of equity and efficiency to medical practice variation as observed in the NHS in the past. The idea of a provider market seemed to produce a neat solution to the search for both equity and efficiency. It emphasises managerial efficiency and encourages more admissions at reduced costs per case. This may not, however, be desirable. Published reports on medical practice variation have highlighted the problem that little is known about the "right" rate in terms of the ratio of benefits to costs. An advantage of focusing on equity, as opposed to managerial efficiency, is that equity raises the issue of differences in rates of treatment by populations for different conditions. This paper suggests that, if the provider market does result in increases in managerial efficiency, this of itself would be unlikely to produce greater equalisation of condition specific rates of treatment. We therefore see the need for directors of public health to examine equity in this way in advising health authorities on commissioning services for their populations.

We thank Richard Rumun and Maria Aristidou for their work on reading and processing the magnetic tape, Tony Swan for his advice, and an anonymous referee for comments on an earlier draft.

1 Department of Health and Social Security. Sharing resources for health in England. The report of the Resource Allocation for health in England. The report of the Resource A

2 Mays N, Bevan G. Resource allocation in the health service. London: Bedford Square Press, 1987.

3 Bevan G, Brazier J. Financial incentives of subregional RAWP. BMf 1987; 295: 836-8.

4 Craig M. Estimating the resources required to train medical students and provide services: a survey of English teaching authorities. Financial Accountability and Management 1987; 3: $135-45$

5 Secretaries of State for Health, Wales, Scotland and Northern Ireland. Working for Patients. London: HMSO 1989.

6 Ham C. Health care variations. London: King's Fund, 1988 7 Sanders D, Coulter A, McPherson K. Variations in hospital admission rates: a review of the literature. (Project Paper 79). London: King's Fund, 1989.

8 Paul Shaheen P, Clark JD, Williams D. Small area analysis: a review and analysis of the North American literature. Health Polit Policy Law 1987; 12: 741-809.

9 Griffith JR, Wilson PA, Wolfe RA, Bishack DP. Clinica profiles of hospital discharge rates in local communities. Health Serv Res 1985; 20: 131-51.

10 Clark JD. Variation in Michigan hospital use rates: do physician and hospital characteristics provide the physician and hospital characteristics

11 McPherson K, Strong PM, Epstein A, Jones L. Regional variations in the use of common surgical procedures: within variations in the use of common surgical procedures: within and between England and Wales, Canada and the
States of America. Soc Sci Med 1981; 154: 273-88.

States of America. Soc Sci Med 1981; 154: 273-88. ii: 1087-90.

13 Wennberg J, Gittelson A. Health care delivery in Maine I Wennberg J, Gittelson A. Health care delivery in Maine I: patterns of use of common

14 Wennberg JE, Freeman JL, Culp WJ. Are hospital services rationed in New Haven or over utilised in Boston? Lancet 1987; i: 1185-9.

15 Office of Population Censuses and Surveys. Classification of surgical operations. Third Edition. London: OPCS, 1975

16 Department of Health and Social Security, Office of Population Censuses and Surveys. 1984 Hospital In Patient Enquiry summary tables. London: HMSO, 1986.

17 Office of Population Censuses and Surveys. Vital statistics: local and health areas, England and Wales 1984. London: HMSO, 1986.

18 Nicholl JP, Thomas KJ, Williams BT, Knowelden J Contribution of the private sector to elective surgery in England and Wales. Lancet 1984; ii: 81-92. 